\title{
Guiding life writers: The supervision of creative doctoral work interrogating personal trauma
}

Sue Joseph \& Freya Latona

University of Technology Sydney

\begin{abstract}
There exists much literature on the student and doctoral candidate relationship across the disciplines. However, there is a gap in understanding this crucial dynamic in the context of creative practices, and an even more pronounced gap interrogating the supervisor to candidate dynamic when a student is conducting life writing involving personal trauma. Despite this, more and more universities are opening their doors to these types of research projects.

In 2014, a final year doctoral candidate in life writing and her supervisor conducted a mini research project about their experience of supervision. The crux of their investigation hinged on the relatively nuanced requirements of supervision when the candidate is writing about personally traumatic themes in their dissertation.

This paper is an extension of their original findings, amalgamating conclusions about what worked in the context of their relationship, given the delicate nature of the subject matter that they were investigating academically, and existing literature on the ethics of such supervision and theories of trauma writing in the context of life writing.

By combining their analysis of their real experiences as supervisor and candidate, and preexisting academic thought on both the requirements of supervision and the differing needs of post-trauma students, the authors seek to contribute to the growing canon within the creative practices on supervisor/candidate relationships, as well as the relatively fraught ethics of the commodification of life experiences within tertiary institutions.
\end{abstract}

Keywords: memoir; trauma narrative; death; grief; supervisor/candidate relationship; narrative enquiry 


\section{Introduction}

When Thomas Couser boldly announced that we may in fact be living in 'the age of memoir', (Couser 2012, p.3), we were forced to consider the importance of the genre, and the subsequent flow on effects of its popularity for writers and consumers. Commercial trends are reflected in universities that offer non-traditional research formats to higher degree candidates. Sometimes, students elect to write about their own personally traumatic experiences within the academy, framed by academic research. For example, the student used in this paper wrote a $\mathrm{PhD}$ on contemporary approaches to memoir as therapy, and included a memoir reflecting on her mother's death in her dissertation. While supervision ${ }^{1}$ is an area that has been well examined, supervisors and candidates understand that a successful doctoral experience and outcome can hinge on the dynamic between both parties, and this changes on a case by case basis. Given the complex scenario that often plays out between supervisor and candidate, it is important to consider the added complexity of a student's own traumatic experience that may form part of their research inspiration or, in some cases, the basis of their full projects. How should supervisor and student interact given the delicacy of the candidate's topic of research? Are supervisors expected to treat the student differently if they are writing about personally traumatic experiences? Should universities be accepting these personally inspired projects ${ }^{2}$ without clearer guidelines addressing the unique working relationship between supervisor and candidate? These are some of the questions addressed in this paper. 
In 2014, a supervisor and doctoral candidate undertook a mini research project, interviewing one another, in order to reflect upon their working relationship. The candidate was in the final year of her doctorate in grief memoir, incorporating creative practice of her own personal experience. This paper follows from their original research, taking their raw data and analysing their results further. It seeks to ground their practice in theory, with a close examination of trauma writing in the context of auto/biography studies, and the ethics of the supervisory relationship.

\section{Trauma writing in the academy}

It is of course difficult to measure how widespread the trend of higher degree students interrogating their own personal trauma in the context of their research is. However, it is possible to track the pattern of the inclusion of autoethnographic modes of research in higher degrees across the humanities (in layman's terms, higher degree research which involves a focus on the self). As Heshusius and Ballard identify in 1996, the research methodology of personal narrative should be considered academically valid and as rigorous as other more formal forms of research (1996, p. 170). Almost twenty years later, we can safely assume even further progress has been made in this regard.

This paper focuses exclusively on higher degree students pursuing autobiographical life writing projects in the arts and social sciences areas, as it is, we suspect, the central arena in the university to attract such research projects. To this end, it is interesting to highlight the work of Alison Lee and Carolyn Williams, who argue that emotion and even irrationality is a vital component of the production of a $\mathrm{PhD}$ in the humanities and social sciences - a necessary evil, perhaps (they argue this about students who are not necessarily writing about personal trauma). As they write: 
... far from being "noise" in the system of pedagogic relations and practices, the emotional and irrational dimensions of the $\mathrm{PhD}$ experience are on the contrary both a necessary condition and an effect of the production of the subject of doctoral study - the licensed independent scholar (Lee \& Williams 1999, p. 6).

It is the view of this paper that, as Lee and Williams argue, a student's struggle to produce a successful $\mathrm{PhD}$ is not necessarily a negative experience, even with the added complexity of a student incorporating a personal narrative on trauma in their work. Bottomley claims the production of a humanities $\mathrm{PhD}$ is:

... a ritual which in many cases becomes psychologically painful and disproportionately demanding' and writes that 'under current conditions gaining a doctorate entails the endurance of severe personal distress for a great many candidates and the output of successful $\mathrm{PhDs}$ is achieved at the expense of a high toll in purely human terms (Bottomley in Lee \& Williams 1999, p. 7).

If we agree with scholars such as Bottomley, then how should we consider students who feel the dual effects of the general stress that seems to accompany the production of most doctoral research and that of drawing upon their own trauma in some way in the production of that research? It is important to note that students and supervisors who undertake higher degree research projects which explore in some way the student's own personal trauma do not necessarily intend for the doctoral experience to enable catharsis or healing for the student, although this may occur incidentally through the process. As Joseph and Rickett note:

[w]hile there is evidence-based research on the efficacy of writing as a therapeutic intervention in various settings, our focus... is to raise questions around the ethics of 
commodifying trauma as a means of gaining a higher degree. One of our primary concerns is the potentially dangerous space it can create for both the academic and the student (Joseph \& Rickett 2010, p. 3).

This paper intends to extend upon these concerns raised by Joseph and Rickett, focusing on both the positive and perhaps unusual aspects of successful higher degree research projects that touch on a student's personal trauma experience and the potential for harm to both supervisor and candidate. There is at present limited resources for students and supervisors who undertake these types of personal projects in the humanities and a lack of analysis by universities that offer such types of research and creative, non-traditional theses options for students.

\section{The ethics of the supervisory relationship}

Brien and Williamson highlight that there exists '...differing expectations of supervisor-student roles and relationships, a factor that seems especially prevalent in the so-called 'non-traditional' discipline areas' (Brien \& Williamson 2009, para 2). Indeed when we look at non-traditional disciplines such as writing and creative practice, the ethics of supervision becomes even more intricate. In the experience of the authors of this paper, standard ethical practice for supervision (guidelines are different across institutions) is important to consider yet somewhat inadequate when applied to supervisory practice for students writing autobiographically on traumatic experience. Reflecting on an autobiographical, practice-led graphic design $\mathrm{PhD}$ theses, Ings argues: 
... the amplification of the personal voice... in research poses issues to both the research student and their supervisor. As a candidate explores territories of the self, their research will encounter distinct ethical, critical and personal challenges that must be insightfully and critically considered (Ings 2014, p. 676).

Arguably, Ing's observations about autobiographical higher degree research in graphic design can be made about candidates in the equivalent life-writing field. However, it could also be argued that a student reflecting on personal trauma through life-writing as part of their doctoral work poses an even greater risk for harm than other mediums. This paper seeks to analyse further Ings' notions of '...ethical, critical and personal challenges...' that can emerge out of autobiographical higher degree research projects that explore personal trauma. Ings also writes:

Traditionally, university ethics committees are concerned with ethics protecting participants other than the researcher [and indeed supervisor]. This is normally a relatively straightforward demarcation. However, where people appear as components in personal narrative, it becomes a little more complex. As characters, they are often 'unknowing' participants and appear as subjectively framed in non-neutrally edited representations (Ings 2014, p. 682).

It is interesting to consider the ethics process for the candidate whose work is analysed as a case study in this paper. The student was not required to seek ethics committee approval from her university to undertake a research project which analysed her own personal grief, or to write her memoir on the subject which formed part of her non-traditional dissertation in life-writing. At the time this was a relief for the candidate, as ethics committee approval can be a long-winded and bureaucratic process. However, in the first year of her $\mathrm{PhD}$, the candidate found she could 
not write about her mother's death as she felt emotionally harmed by the process. Her supervisor understood, and they discussed options for an alternative creative project that could accompany her dissertation. As the student's background was in print journalism, both the supervisor and student devised a new type of project on mother loss. The student would interview Australian celebrities who had lost their mothers before adulthood in order to explore grief culture. She hoped she could communicate her ideas through the voices of others rather than her own. This project required intensive ethics committee approval, and was not granted clearance, due to the potential for harm to interview subjects given the topic of mother loss and grief. (As an aside, this did not matter because by this stage, the student had rekindled her desire to write her own memoir). What is interesting for this exploration on life-writing, trauma and supervisory ethics is that, according to the humanities faculty, the ethics was fraught when considering harm to others, but not worthy of ethics committee validation when examined autobiographically at the time.

This paper does not argue that this decision by university ethics not to consider autobiographical projects which examine personal trauma was neglectful. We merely raise this anecdote as an exemplar of how these projects can 'slip under the radar' at universities, despite the high level of potential harm for the student and the subsequent extra requirements placed on their supervisors, who become aware of the student's traumatic life narrative and must ensure their student's emotional, as well as intellectual, welfare.

The below set of interviews ${ }^{3}$ interrogates the issues from both supervisor and student perspectives in order to illuminate potential harm for both parties, and conversely, potential for a fruitful and meaningful supervisory relationship. 


\section{The Interviews:}

\section{Supervisor to candidate}

Q: When you first walked into my office in 2009 with that scrap of paper with Chinese/alternative medicine scribbled on it, did you have any idea that what you really wanted to be writing about was your mother?

A: I can't say that I consciously wanted to write about my mother... but ... what was on the scrap of paper was I wanted to research - alternative therapy in Australia. Yes. And then you didn't really like the ideas - they were not real ideas and I got offended; I had just met you. And then you said, 'What's going on?’ And I explained...

Q: I remember you said to me, 'I had a really hard time in my undergraduate degree,' and then you very simply told me that your Mum had died almost a year ago to the day you were in my office?

A: I think I remember you saying something really simply which was, 'Why don't you write about that?' or 'Would you want to write about that?' But it was so direct and so disarming and so sensitive really; I think you could see it, you picked something up. And then it was like a huge release physically and I just said yes.

Q: You arrived in my office one day about four months into your Honours year and you said you could not write it anymore. I thought the psychic injury had become too much; instead, your dilemma was writing without your mother's approval or permission; without your deceased mother's approval. We devised an epistolary thread to see if that helped. Can you explain how it helped you to keep writing or if it did? 
A: I can't remember that day when I decided to do the epistolary thread, but I do remember thinking about it now how important it was and still is really to the work now that it's a Doctorate.

Q: Do you remember what you said to me the next time I saw you, because I checked in with you about how it was going? You said it was like writing with her rather than about her. The relief; your body, your eyes, everything just changed.

A: I mean now I feel like I've written it with her: the whole thing. I actually think we're writing it together, without knowing how exactly that works...But it was really important that kind of suggestion to incorporate my mother into it.

Q:You said to me it was like she was a teacher and you were the student; just mother/daughter communicating at a very tough time, keeping each other up, saying some really strong emotional things to each other. And in a way now its testimonial.

A: I'm comfortable with it now but I do think still apart from the incorporation of the emails being a strategy for me to feel like she was writing it with me, I still feel like it's never going to be ethically 100 percent okay to publish someone else's writing, and particular emails are very personal.

Q: Which is my next question; from an ethical point of view did the epistolary thread with emails and letters from your mother woven throughout your text completely alleviate that feeling of writing without her permission? 
A: No, no, and it's never going to be 100 percent and I think that's with all memoir. I vacillate between feeling like I've exposed her too much, and then not so much. I do have days when I panic about it. It'll always be like this.

Q: How hard was it to step from your Honours degree into your Doctoral degree and develop more deeply this distinctly painful and ongoing interrogation of grief and death?

A: It was really hard, it was horrible. I remember thinking I have nothing left to write, like I just have nothing left in me, and I don't think I was in a good place emotionally actually at that time.

Q: I think you launched yourself into the theoretical study of death?

A: I did. And that was actually my proposal to the faculty. The proposal looks nothing like what it is now, almost finished. The proposal didn't really talk about what I would do with my creative; it talked about this kind of thanatological exploration on death. Even though I had made leaps and bounds in the Honours degree and finding out how much writing as therapy works and things like that, and even though it was a success, it didn't quite translate over to the next degree.

Q: I'm interested in you saying you had nothing left to write. And how much have you written now?

A: I know, 100,000 words plus more... and it takes a separate tone, it's a different tone. I think I'm further away from it first and foremost and in a better emotional position, although not always; you don't have to be 100 percent emotionally okay. In fact, being upset sometimes can make the work quite raw and add things to it. But I do think making up that process of 500 words a day was the turning point completely.

Q: I think I said to you 'fragments, write fragments, that's what you do well'. 
A: I remember thinking 500 words a day because it's about a page. And I can do it really quickly, so I did it really quickly. And that's the complete turning point, that's why this whole thing is possible, it's because I did it every day. And there is interesting philosophy behind the daily writing, just like there's philosophy behind daily exercise or daily anything. Apparently it's in the 'daily' that really makes a part of habit, but then it became like an outlet and a friend within about a week.

Q: So do you believe in writing as therapy now?

A: Yes. They have theories about writing being therapy; the studies say that writing is therapy when you create a narrative out of trauma. Listing and writing in fragments that don't have a narrative are not affective, that's what the studies say. What I say, in order to get to the narrative of trauma you actually have to do fragments first, or kind of a more disjointed process, because that's the way trauma often presents itself. It's not a narrative at first, it can't be. I mean it's so common that people can't remember properly or have disjointed memory or false memory even. But it's through writing that you start to see the narrative in it - but you can't write a narrative at first, you sort of have to go through this process first. That's my theory.

Q: Which you've tested obviously?

A: Yes, and it kind of ties in with the psychology behind writing as therapy.

Q: Has the process of surrounding yourself with the literature and literally going to work each day and thinking about your mother made the pain worse or better? Because I think your conclusion in your Honours was that it didn't work for you.

A: I'd say no...I mean to go back to the writing as therapy, it did take a long time for me to realise that it worked. So what I learnt later was you really have to stick with it. 
Q: I have co-developed a pedagogical model of supervision pertinent to trauma life writing and applied it to you from a very early stage of our supervisory relationship. You are aware that it entails checking in on a more personal aspect of the process of your Doctoral undertakings. Have you found this intrusive at any time, and I guess the next question; could/should I have delved more deeply? Supervising someone who's doing life writing framed by trauma is different to supervising someone who's not...

A: I personally have never found you intrusive. If I had found you intrusive I certainly wouldn't have come back for a Doctorate with you knowing that it would be another three and a bit years. And I think you've bridged the gap well for me between being personal enough. But I think that if you had pushed me further in terms of maybe a little bit more about my grief in kind of indepth way and I sort of broke down in front of you consistently, I think that may not have helped me personally because I'm not a break-downer.

Q: To be honest I don't think I ever would do that because I don't have the skills to manage that. I would never really push anyone on their level of grief because that's not what I'm trying to do, I'm just trying to find out that you are surrounded by a therapeutic scaffold to hold you up while you keep doing this. And I guess the other thing that I do is I check in a lot, I sort of try and be in contact a lot, which possibly is quite intrusive and boring. And I try and do it personally so I can see people's eyes when I ask certain questions just to see what they do. So finally, have you felt 'safe' while writing on your mother's death; or have you felt exposed and vulnerable? Have you felt in any way protected by the supervisory process?

A: I have felt both safe and unsafe. Having a supervisor like you has been an incredible gift. However, to have a supervisor also means that I am writing in the university context - I am more exposed this way than if I was just writing alone, for my own purposes. I guess I'm thinking 12 | P a g e 
about my dealings with other academics who clearly do not have training in handling students who are writing about personal and traumatic themes. I haven't dealt with them often, but when I have, it has actually been harmful. It's interesting because it's a great comparative tool, really. I can see the difference in how you deal with me and talk to me and how they do. So, yes. Protected by the supervisory process, but not by the larger university/departmental process.

\section{Candidate to supervisor:}

Q: This follows on from a question you had - what is your approach to supervising students who are writing about traumatic subjects?

A: I, with colleague Dr Carolyn Rickett, co-developed a model which I've since added to. It was a four point model. It's now a five point model. Basically the philosophy behind it is what we were talking about then. I believe that supervising someone who is life writing in trauma is a different pedagogy to supervising someone who's not and that you have to cross... a line that you would never cross in supervision pedagogy where there is no trauma narrative. I have to make sure there's a therapeutic scaffold around each person who comes to me who wishes to write in trauma narrative. I believe that the university has no right to commodify something like trauma narrative in a degree unless it is ethically handled. Unless a different model of supervision is put in place. As an academic I'm not skilled at all in how to handle medical trauma but I've done a lot of research on it and what I can do is work side by side with the people I hope my students have in this therapeutic scaffold, ie. a loving partner who gets it, a mum or a dad who gets it, a therapist seen regularly, psychiatrist, medications. I never ask about medications but I'm figuring if someone's seeing a psychiatrist they've got meds and if they're seeing a psychologist they may have or may not have. It's the person, the scaffold and alliance around the candidate. So that I know when they're not with me and we're not talking they can go 
away, do their work and reach out for the help and I also say anytime, just tell me if it gets too hard.

Q: Well there's one really important thing that I think made me know I could write trauma narrative with you as a supervisor, which was you always made it really clear that you care more about the student than you do about their work.

A: But again this lends itself to my own personal philosophy or ethos around supervising trauma narrative. You've got to get skilled, but I don't mean medically. I can walk alongside paramedicals that my students hopefully all have - and I do ask in the first session. So again I'm stepping over this huge personal line but I think it's necessary. If there's a trauma narrative inherent in the piece of writing that is personal or happened to someone they knew, as far as I'm concerned that's supervising trauma narrative whether it's fiction or non-fiction.

Q: That leads me to how you bridge the gap between acting as a traditional academic supervisor, which you have to do to get a work through in creative practices, and being this trauma supervisor. How do you ensure that the work is a publishable standard while being sensitive to a student's experiences?

A: It's a really good question, and the question really is: Am I there as a therapist? No I'm not. I am there as an academic practitioner who is working as an editor for publishable work. I'm definitely looking out for the academic rigor of both the exegetical material but also the creative rigor of the non-traditional component or the creative artefact. I try and build a relationship, which is above and beyond with each of my candidates in trauma narrative, of trust. So when I say to somebody, you really can't put that there, I'm open to negotiation. I will talk about it. It 
will be my opinion but if it's a strong one I'll really argue my position. Checking in on their eyes and their body language, all the time so that in my meagre knowledge I think they're alright.

Q: I'm going to ask you now about me. Has your approach in supervising me changed over the years?

A: You were the first student I had after a difficult supervisory experience and I never wanted to risk endangering a student's psyche again. I would rather step away from my job. I did take a risk with you and I sort of experimented on you but at the end of the day you always were more important than anything else, even when I didn't know you. At the end of the day your health, your psychic health is far more important to me. I hope you never left me feeling worse off. I'm sure you left pieces of writing feeling pretty ragged at times but that's my expectation that you would. That's the nature of trauma writing and that's where your therapeutic scaffold comes in. I would really question proceeding if a student didn't have the ability to reach out for help; I'd probably take it up with student health at the university and higher up in the graduate school if I thought a student was really in danger, psychically.

Q: I think partly why it worked well and is working well with us, is because you're a mother, and you can correct me if I'm wrong. You're a mother of daughters around my age and I was writing about the death of my mother and you had empathy which I could see was really palpable and still is. Was it ever difficult for you personally when reading my work? Did it put you in a position of vulnerability and this is a personal question but it may have affected you also as a mother because you're reading in depth kind of a musings of a daughter who's grieving hers?

A: Absolutely. I mean my heart, not as an academic, but as a mother, as a woman and a mother, went out to you. There's never been a time when I haven't been so aware of the shoes you're walking in and praying for want of a better word that my kids never have to walk in them. That I 
was lucky enough never to walk in them, and what a fragile place it is, and what a fragile place it is between you and I, because of this.

Q: Do you think that is part of it?

A: Okay the other thing I'd like to say here is that my empathy is with Kris [the candidate's mother]. Ever since you brought her into my life she has been a real person to me. I think, what would she want for you, and how would she want you to be doing this, and what would she want you to write? She's been the third person in the room every time I meet you. She really has. I would say that definitely she's an entity in our relationship and I hope she approves of how I've handled you and your work.

Q: So, then, what do you regard as the most important qualities of the supervisor of trauma narrative?

A: Empathy, trust, patience and imagination. I do think you have to see the student or the candidate, that their emotional and psychic health is more important than anything else. I think trust is huge. You've got to be able to trust your supervisor. Because I believe in stepping over that personal line, you've got to be able to trust your supervisor- that what you say and what you tell them is confidential and that they understand, that they're not sort of rolling their eyes and thinking, oh god. And authenticity, you have to be authentic.

Q: So how do you supervise your doctoral writing students who aren't writing about personally traumatic experiences differently to those who are?

A: I don't have to ask them about therapists or supportive partners or parents or friends or meds or psychiatrists. I don't have to know anything about their psychic health I suppose or their 
emotional health unless it comes up in some other way and they want to share that with me and if they do, if it's got no impact on their writing...

Q: Are you more draconian?

A: Am I tougher? No I'm not actually. I still believe it's just different. How can I explain it? I still believe in the independent researcher. That the candidate is the independent researcher and that they overtake me in terms of expertise and knowledge at some wonderful time during the execution of the dissertation. Am I more draconian? No. I'm empathetic about any life really.

Q: Do you think you got that philosophy from having to supervise students over the years on trauma? I know a lot of people with supervisors and hear a lot about it and your strategies are notably different.

A: One thing I will share with you is that when I did my doctorate, despite having supervisors who I enjoyed and liked, I felt very isolated and I never want anybody under my auspices to feel isolated, fearful, like a failure, like it's all hopeless, or like they don't know what they're doing. I just never want anyone to feel like that and that's a philosophy beyond trauma narrative. So I guess it's come from that really.

Q: Do you sympathise to any extent with more traditional academics, who see the higher degree and writing about personal subjects, particularly traumatic ones, as incompatible?

A: No. I believe a university is a place of learning. It's a place of thinking. It's a place of new knowledge. There are a couple of theorists ${ }^{4}$ who say this is the age of trauma. Many social taboos have been broken down. Many damaged people are needing to speak, needing to be heard. There's a lot of voicelessness which is being remedied through life writing, through a 
non-traditional dissertation. A lot of this memoir work has come out of universities around the world through non-traditional dissertations. I see it as a good thing. I see it as a vehicle for finishing off these taboos, and a lot of life writing around trauma particularly is universal. I mean, everyone experiences death at some point. You experienced it very early. Let's hope everyone doesn't experience all the other traumas that I've been supervising. So I think it's very ungenerous to be so prescriptive about what you can and can't do in a university...I think if the academics who are supervising this sort of narrative are rigorous enough, it's not watering down any sort of doctoral standard of excellence. To answer these academics, I would suggest reading some of the work that we're producing that underpins the life writing of non-traditional PHDs or non-traditional doctorates. I don't understand the argument and I don't understand the lack of generosity.

Q: It must take more energy out of you as a supervisor taking on students like me who require academic direction but also a delicate and empathetic approach, particularly when you are juggling more than one student at a time. What are your strategies for maintaining a necessary distance and detaching from trauma generally?

A: I am lucky enough to have a very close dear friend who's a psychologist and we get together regularly. So I have my own sort of inbuilt therapist. I need it. I do need it.

Q: Would that be a suggestion from you to other supervisors?

A: Look there is vicarious trauma in this sort of supervision. I must admit, since I've set up the model and started practicing on you onwards, I haven't been in need of help. Before that I didn't know what to do really. I was pretty upset a lot of the time with the first student with whom I had a difficult experience, but I would suggest anybody who is writing trauma narrative of their own 
or who is supervising trauma narrative has their own therapeutic scaffold. It means if something's bothering you, you've got someone you can go and knock on their door. It can be your best friend. It doesn't have to be a therapist, although with deep vicarious trauma I would recommend a therapist.

\section{Pedagogical Reflection and analysis of results}

As noted earlier in this paper, the notion of doctoral candidates drawing on personal experience to inform and contextualise their research is not a new phenomenon. By extension, it is also not uncommon to see candidates (particularly, we suspect) in the creative writing arena exploring issues relating to their own experience/s of personal trauma for their research. Just as authors across the centuries have delved into their own life stories (good and bad) to create content for their novels and creative non-fiction outputs, higher degree students enrolled at universities to learn more about the writing medium and its possibilities for personal and professional expression, also naturally draw on the advisory adage to 'write what you know'.

So, if candidates in universities are writing about personal experience/s, and as such, occasionally delving into traumatic experience, it is pertinent to examine closely the ethics of academic supervision of these candidates. While writing departments in universities are offering research degrees that allow students to examine their own trauma through creative thesis work (which the authors of this paper believe to be reflective of the wider writing and publishing world outside of the walls of the university), they do so across the board without necessary guidance for supervisors who have to deal with the added complexity of their student's psychological and emotional stability, as well as their research quality. 
The above interviews reveal much about the candidate/supervisor relationship when both parties are involved in academic work around personal trauma on the part of the candidate. While these interviews provide data that speak only for this particular two person team, we believe some of our questions and answers raise wider discussion points for other supervisors and candidates who may be working in the same field. Namely, these themes revolve around the importance of an open dialogue between supervisor and candidate about the particularity and delicacy of their topic of investigation; the necessity for the supervisor to have a framework of supervisory practice and strategy (however informal) to revert back to when working with the candidate; and, perhaps more controversially, the acknowledgement of the wider principle that frames tworking relationship - that the candidate's (and supervisor's) emotional wellbeing is more important than their academic pursuit.

It is important to acknowledge what cannot be statistically measured or implemented across universities as a 'model'. The supervisor and candidate in this case happened to interact intuitively together, moving through the differing stages of their working relationship with relative ease despite the student's subject of research. They connected personally and professionally, and this is a scenario that was instrumental to the success of both the student's research degrees. The student reaffirms this, believing that she would not have felt comfortable writing her creative and theoretical work without the support of this particular supervisor. If she had undertaken her projects with a supervisor who, for example, had no experience in pursuing doctoral degrees of a personal nature, or who treated her formally and without particular regard for her emotional well-being, she believes she would have felt exposed and vulnerable, and potentially unable to complete either research degree. Perhaps this can be played out similarly 
across universities that offer creative practice as higher research. Perhaps supervisors whose research interests are already in life-writing would be aware of the sub-genre of "misery memoir', and as such, better equipped to supervise students pursuing research and creative output in the field.

It is, according to the data presented in this paper, not necessary or appropriate, for the supervisor to act as a pseudo counsellor for the student. This paper certainly does not advocate for a supervisory model that prioritises a supportive supervisor to student relationship over the production of rigorous academic work produced to a high standard. However, as the data above shows, there existed in their working relationship, no competition between these two ideals - the student produced a high standard of research work, and the supervisor and candidate remained aware of the potential emotional volatility for the student at various stages of her doctoral candidature.

There is no necessary conflict between academically rigorous research and output and caring for candidates investigating their own personally traumatic experiences. After all, research interests that include reflection on personal trauma - memoir as therapy for grief, for example - pertain to well established pre-existing areas of scholarly investigation into genre and psychology, among other fields. It would be neglectful for universities to ignore these fields because of potential harm to the student and largely they do not. It is not a departure to note that most students pursue subjects for doctoral degrees that stem from a personal and/or professional interest and/or experience. Indeed, students are often advised to select topics that will sustain their passion and interest for three or more years, full time. 
In their exploration of their own supervisory dynamic, Chapman and Sork write: '...reactions from some traditional scholars in the field included allusions to "navel gazing" and the "self indulgence" of our use of personal narrative as a framing methodology' (2001, p. 95). The same criticisms can and are made about life-writing in and out of the academy, and could be made about this mini-research project. However, this paper, by utilising the 'personal narrative' of a supervisory relationship as a 'framing methodology' to tease out ethical and personal concerns about the incorporation of personal trauma in writing studies, aims to provide an insight into what can be complex and ethically grey academic territory, and gently suggest strategies for future academic to student partnerships that interrogate personal trauma.

\section{References}

Brien, Donna Lee. \& Williamson, Rosemary. 2009. 'Supervising the Creative Arts Research Higher Degree: Towards Best Practice, TEXT (Special Issue Number 6), p.1-4. http://www.textjournal.com.au/speciss/issue6/content.htm

Chapman, Valerie-Lee \& Sork, Thomas J. 2001. 'Confessing Regulation or Telling Secrets? Opening up the Conversation on Graduate Supervision', Adult Education Quarterly, Vol. 51, No.2.

Couser, Thomas. 2012. Memoir: An Introduction, Oxford University Press, New York.

Lee, Alison. \& Williams, Carolyn. 1999. 'Forged in Fire: Narratives of Trauma in PhD Supervision Pedagogy', Southern Review: Communication, Politics \& Culture, Vol. 32, No.1, pp. 6-26.

Heshusius, L., \& Ballard, K. (Eds.). 1996. From positivism to interpretivism and beyond: Tales of transformation in educational and social research. New York: Columbia University, Teachers College Press.

Ings, Welby. 2014. 'Narcissus and the muse: supervisory implications of autobiographical, practice-led PhD design theses', Qualitative Research, Vol.14, No.6, pp.675- 693.

Joseph, Sue. \& Rickett, Carolyn. 2010. 'The writing cure?: ethical considerations in managing creative practice life-writing projects', Strange Bedfellows: Refereed Conference Papers of the 
15th Annual AAWP Conference, 2010,

http://d3n8a8pro7vhmx.cloudfront.net/theaawp/pages/85/attachments/original/1385080442/Josep

h_Rickett.pdf?1385080442

Joseph, Sue. \& Latona, Freya. 2014. 'Perspectives: Writing and supervising trauma narrative in tertiary studies', Minding The Gap: Writing Across Thresholds And Fault Lines Papers - The Refereed Proceedings Of The 19th Conference Of The Australasian Association Of Writing Programs, 2014, Wellington NZ.

https://d3n8a8pro7vhmx.cloudfront.net/theaawp/pages/156/attachments/original/1427068942/Lat ona_and_Joseph_perspectives_supervising_and_writing_trauma.pdf?1427068942

Miller, Nancy K and Tougaw, Jason 2002 (eds) Extremities Trauma, Testimony, and Community, University of Illinois Press, USA

\section{Notes}

1 The term 'supervisor', essential to this paper, refers to the primary academic contact and mentor throughout the thesis research period of a doctoral candidiate. The supervisor/s (also known as doctoral advisors in the US) guide the student through their studies, handling both research and administrative queries.

2 The term 'life-writing' is defined in this paper as writing that is autobiographical in nature, recording a life event or events from the perspective of the author. Importantly, we define 'life-writing' as distinct from didactic autobiography, preferring to focus on creative non-fiction forms of life-writing, such as memoir. ${ }^{3}$ These interviews were first partially published in the Refereed Proceedings of The 19th Conference of The Australasian Association of Writing Programs 2014 (Joseph \& Latona 2014).

${ }^{4}$ Miller \& Tougaw, 2002: 1-2 